\title{
Inverse determination of the heat transfer coefficient distribution on a steel plate cooled by a water spray nozzle
}

\author{
A. Cebo-Rudnicka, Z. Malinowski, T. Telejko \& J. Gielzecki \\ AGH University of Science and Technology, Poland
}

\begin{abstract}
Water spray cooling plays an important role in the steel industry. Continuous casting lines are equipped with the system of water spray nozzles installed in the secondary cooling zones. In the hot rolling mills the spray or laminar cooling systems are employed to reduce the strip temperature before coiling. A suitable rate of cooling must be employed to ensure a proper temperature drop of the worked out material in order to achieve desired properties. Quality of the numerical simulations of the temperature field of the cooled object strongly depends on the thermal boundary conditions. In the literature only average or maximum values of the heat transfer coefficient while spray cooling are available. The experimental stand, numerical models and dedicated software have been developed to study the heat transfer coefficient distribution on the surface of the steel plate cooled by the water sprays. The steel plate is heated in the electric furnace up to the temperature of $907^{\circ} \mathrm{C}$. Next, the hot plate is pushed to the cooling chamber and cooled by the water spray nozzle. The plate temperature has been measured by the 25 thermocouples. The measurements have been employed to determine the distribution of the heat transfer coefficient on the plate surface. The inverse method based on the three dimensional finite element model of the heat conduction in the plate has been employed. The finite element model is based on nonlinear shape function. The heat transfer coefficient varies significantly over the cooled surface of the plate and strongly depends on the plate temperature.
\end{abstract}

Keywords: heat transfer coefficient, inverse method, spray cooling, three dimensional model. 


\section{Introduction}

Plate and strip hot rolling lines, as well as the continuous casting lines are equipped with water cooling systems used to control the hot material temperature. These systems have a great importance in terms of final properties of the product. The desired rate of cooling can be achieved by water spray cooling applied to the hot surface of a strip (Malinowski et al. [1], Tacke et al. [2]). The heat transfer process that occurs between strip surface and cooling fluid while jet impingement includes boiling phenomena. There are film, transition and nucleate boiling regimes. The details of the boiling heat transfer and jet impingement can be found in (Bejan [3], Webb and Ma [4]). The most suitable manner of characterizing heat transfer process is to determine the heat transfer coefficient $h$ (HTC), which allows calculating heat flux using a simple Newton's law of cooling. Unfortunately, the direct measurements of the HTC are not possible for the complexity of the process, so the inverse solution shall be applied to reach the goal. The boundary inverse heat conduction problem (IHCP) can be formulated and HTC would be the searched parameter in optimization procedure. To use the IHCP the measurements at the laboratory stand are needed. The parameter which is measured while the experimental tests is the temperature at selected points of the cooled body. Then, the measured temperatures are employed in numerical inverse procedure. In the paper, the results of the HTC calculation have been presented. The results were obtained on the basis of experimental test performed for the water spray cooling of the hot steel plate. Inverse solution to the HTC was possible due to the developed dedicated software.

\section{Inverse model}

The heat transfer coefficient on the hot surface of a plate cooled by the water spray has been determined from the inverse solution to the heat transfer problem. The objective function has been formulated in the following way:

$$
E\left(p_{i}\right)=\sum_{m=1}^{N t} \sum_{n=1}^{N p}\left(t e_{n}^{m}-t_{n}^{m}\right)^{2} .
$$

where:

$p_{i} \quad-$ vector of the unknown parameters,

Nt $\quad$ - number of the temperature sensors,

$\mathrm{Np} \quad-$ number of the temperature measurements performed by one sensor at the time of cooling,

$t e_{n}^{m} \quad-$ the sample temperature measured by the sensor $m$ at the time $\tau_{n}$,

$t_{n}^{m} \quad-$ the sample temperature at the location of the sensor $m$ at the time $\tau_{n}$ calculated from the finite element solution to the heat transfer problem.

The objective function given by eqn. (1) defines the difference between measured and calculated temperatures. The unknown parameters $p_{i}$ have been determined by minimizing the objective function. The conjugate gradient method and the variable matrix method have been employed. The derivatives 
of the objective function with respect to the unknown parameters $p_{i}$ have been estimated numerically. The finite difference form of the first derivative has been employed in computations. The sample temperature field has been computed from the three dimensional solution to the heat conduction problem in a plate.

The boundary condition given by the heat flux distribution on the cooled surface of the metal plate has been expressed as:

where:

$$
\dot{q}=h\left(x_{2}, x_{3}, \tau\right)\left(t_{s}-t_{a}\right),
$$

$t_{s} \quad-$ cooled metal surface temperature,

$t_{a} \quad$ - cooling water spray temperature.

Variation of the heat transfer coefficient at the metal surface cooled by water spray has been approximated by:

$$
h\left(x_{2}, x_{3}, \tau\right)=\sum_{i=1}^{8} N_{i} P_{i}(\tau)
$$

In eqn. (3) $N_{i}$ are quadratic shape functions serendipity family:

$$
\begin{aligned}
& N_{1}=\left(1-\xi_{1}\right)\left(1-\xi_{2}\right)\left(-\xi_{1}-\xi_{2}-1\right) / 4, \\
& N_{2}=\left(1-\xi_{1}^{2}\right)\left(1-\xi_{2}\right) / 2, \\
& N_{3}=\left(1+\xi_{1}\right)\left(1+\xi_{2}\right)\left(\xi_{1}-\xi_{2}-1\right) / 4, \\
& N_{4}=\left(1-\xi_{2}^{2}\right)\left(1+\xi_{1}\right) / 2, \\
& N_{5}=\left(1+\xi_{1}\right)\left(1+\xi_{2}\right)\left(\xi_{1}+\xi_{2}-1\right) / 4, \\
& N_{6}=\left(1-\xi_{1}^{2}\right)\left(1+\xi_{2}\right) / 2, \\
& N_{7}=\left(1-\xi_{1}\right)\left(1+\xi_{2}\right)\left(-\xi_{1}+\xi_{2}-1\right) / 4, \\
& N_{8}=\left(1-\xi_{2}^{2}\right)\left(1-\xi_{1}\right) / 2 \text { for } \xi_{1} \in(-1,+1) \text { and } \xi_{2} \in(-1,+1) .
\end{aligned}
$$

The cooled surface has been divided into rectangular elements. For each element eqn. (3) has been used to approximate heat transfer coefficient distribution. Functions $P_{i}(\tau)$ describe the heat transfer coefficient variation at nodes of elements in the time of cooling. At each element node the function $P_{i}(\tau)$ has the following form:

$$
P_{i}(\tau)=\sum_{j=1}^{3} W_{j}(\eta) p_{j}, \quad \text { for } \eta \in(0,1)
$$

In order to improve the approximation accuracy the time of cooling is divided into periods for which $\tau \in\left(\tau_{1}, \tau_{2}\right)$ and the local coordinate $\eta$ is given by:

$$
\eta=\frac{\tau-\tau_{1}}{\tau_{2}-\tau_{1}}
$$

In eqn. (4) shape functions $W_{j}$ have the following form:

$$
\begin{gathered}
W_{1}=1-3 \eta+2 \eta^{2} \\
W_{2}=4 \eta-4 \eta^{2} \\
W_{3}=2 \eta^{2}-\eta \quad \text { for } \quad 0 \leq \eta \leq 1 .
\end{gathered}
$$


The set of unknown parameters $p_{j}$ which have to be determined by minimizing the objective function given by eqn. (1) is composed of values of the heat transfer coefficient $h(\tau)$ at nodes of approximation. The set of parameters $p_{j}$ which makes the error norm $E\left(p_{i}\right)$ stationary gives the distribution of the heat transfer coefficient over the metal plate cooled by the water spray. Further, the distribution of the heat transfer coefficient and its variation in the time of cooling has been defined.

\section{Experimental procedure}

The measurements have been performed for the steel plate heated up in the electrical furnace to the uniform temperature of $t_{o}=907^{\circ} \mathrm{C}$. The thickness of the plate was $8 \mathrm{~mm}$. The plate was $300 \mathrm{~mm}$ long and $210 \mathrm{~mm}$ wide. The chemical composition of the steel was as the following: $0.2 \% \mathrm{C}, 1.5 \% \mathrm{Si}, 2.0 \% \mathrm{Mn}, 19 \%$ $\mathrm{Cr}, 13 \% \mathrm{Ni}$. The plate has been placed vertically to the water spray nozzle. The water spray nozzle MNQ 1040 T1SH type [5] has been employed while cooling. The water pressure was $1 \mathrm{bar}$ and the water flow rate was $0.000035 \mathrm{~m}^{3} / \mathrm{s}$. The nozzle has been located $120 \mathrm{~mm}$ from the plate surface approximately at the centre of the plate. The plate temperature has been measured by 25 thermocouples located $2 \mathrm{~mm}$ below the cooled surface. The thermocouples deployment over the cooled plate have been presented in figure 1 .

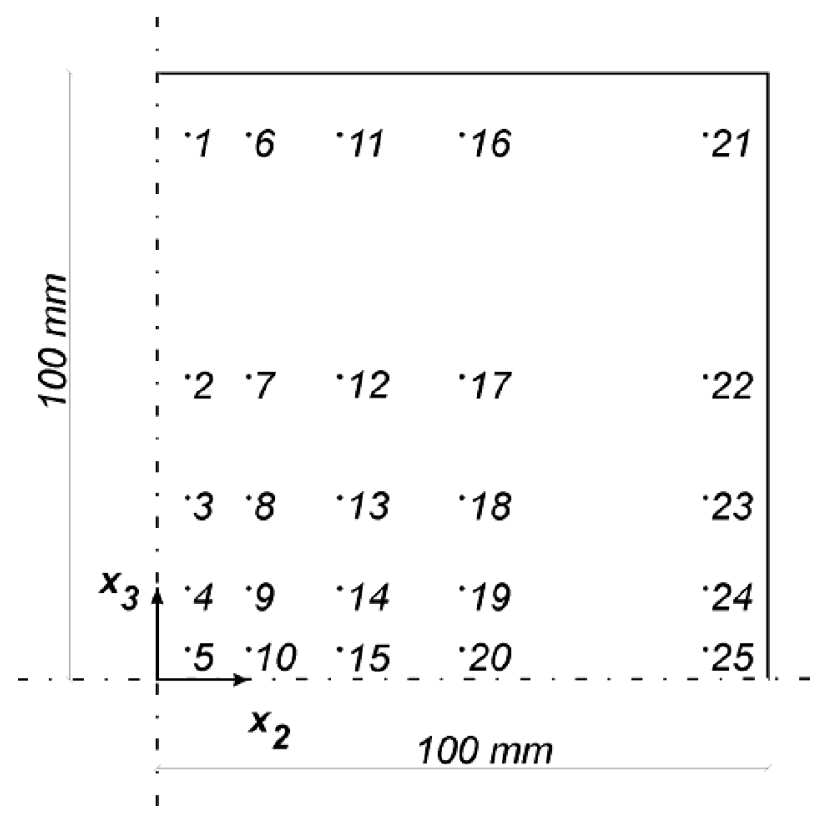

Figure 1: A quarter of the steel plate with the location of 25 thermocouples.

Due to symmetry of the nozzle the temperature measurements and numerical computations have been limited to one quarter of the plate. 


\section{Results of the inverse solution}

Several parameters have an influence on the heat transfer coefficient while water sprays cooling process. The surface temperature of a cooled object and water flux distribution over a cooled surface are numbered to the ones that are the most important. The other parameter which should also be taken into account is the cooled object orientation versus the spray nozzle.

In the beginning stage of the spray cooling process of a hot metal, impinging water spray steadily cover hot metal surface. The distribution of the water flux depends on the type of the spray nozzle. As a result of water droplets contact with the hot metal surface, the liquid temperature in the contact zone is raised above its limiting superheat temperature and the vapor film develops. It results in a low quantity of heat removal from the cooled surface and a low decrease in the surface temperature.

In figure 2 the temperature distribution over the cooled plate after $60 \mathrm{~s}$ of cooling has been presented. The temperature distribution has been obtained by the inverse solution to the measured temperatures by 25 thermocouples. The obtained results have shown that the temperature distribution is nearly symmetrical to the spray nozzle axis. After $60 \mathrm{~s}$ of cooling the highest decrease in plate temperature is observed at the distance of $20 \mathrm{~mm}$ to $40 \mathrm{~mm}$ for the axis of the spray nozzle. It was caused by the water flux distribution resulted from the type of spray nozzle employed.

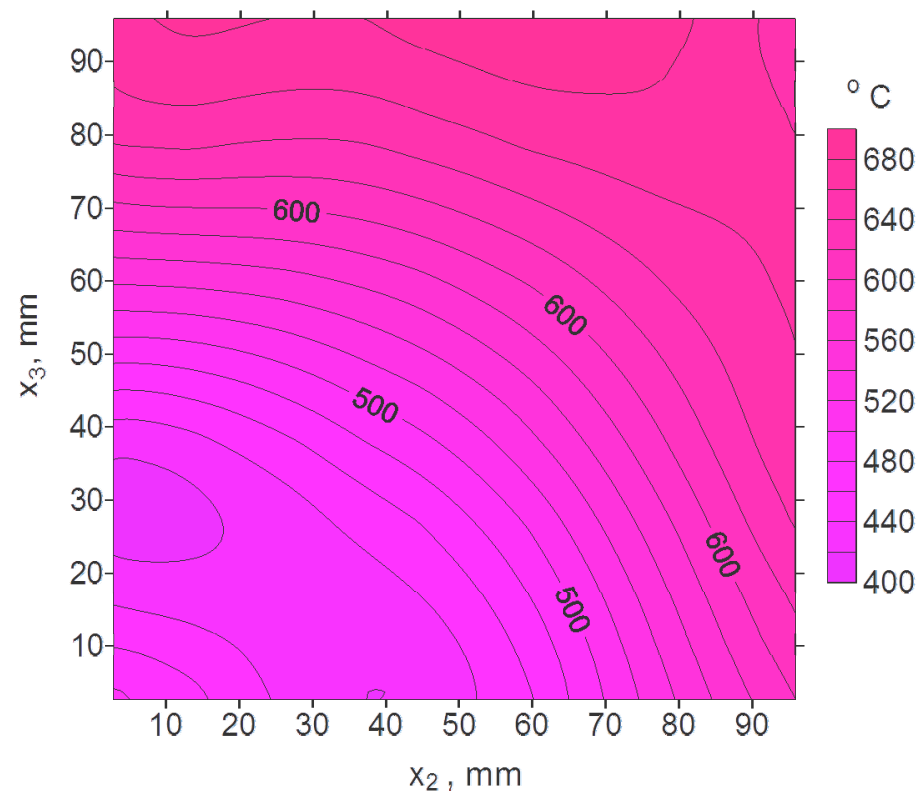

Figure 2: Temperature distribution over the cooled plate after $60 \mathrm{~s}$ of spray cooling process. 
The results of the plate surface temperature distribution after $100 \mathrm{~s}$ of spray cooling process has been presented in figure 3. It can be deduced from the temperate distribution over the cooled plate that the water sprays have covered the area at the distance of about $80 \mathrm{~mm}$ from the nozzle spray axis.

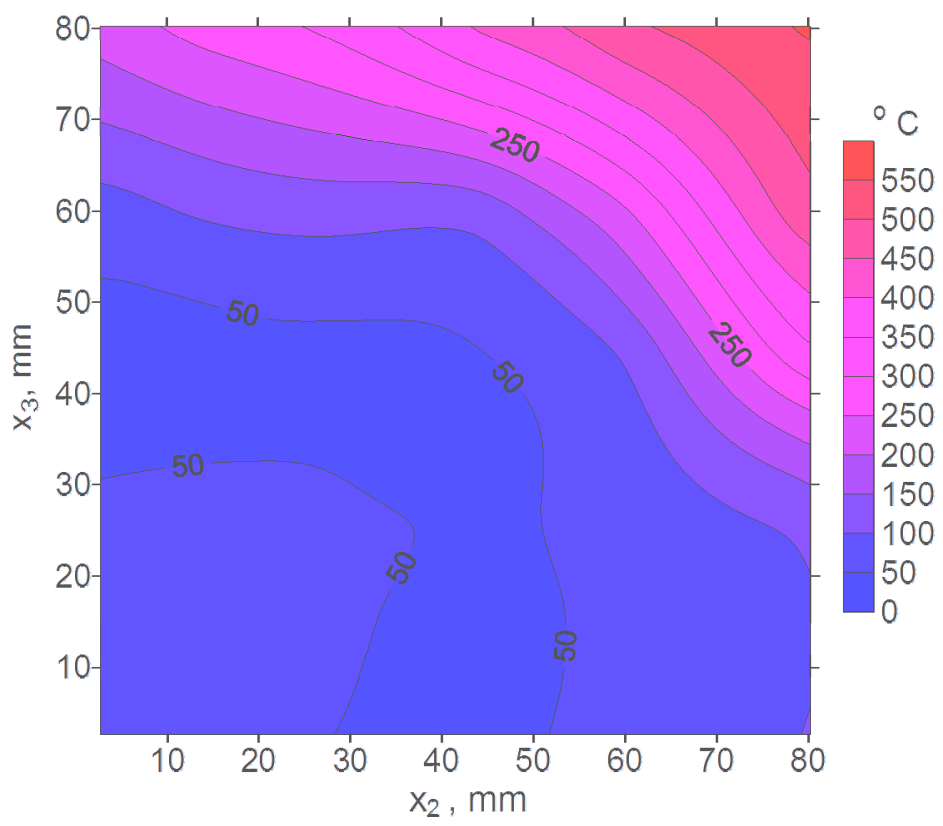

Figure 3: Temperature distribution over the cooled plate after $100 \mathrm{~s}$ of spray cooling process.

In figure 4 the variations of temperatures measured (red, dashed lines) by the thermocouples: 13, 14, 15 and 16 have been compared to the temperatures determined from the inverse solution (blue lines) based on three dimensional finite element heat transfer model. The temperatures at the thermocouple locations determined from the inverse solution fit the measurements with a good accuracy. The average difference between measured and computed temperatures is of $7.69^{\circ} \mathrm{C}$.

In figures 5 and 6 the HTC distributions over the cooled plate after $60 \mathrm{~s}$ and $100 \mathrm{~s}$ of cooling have been presented. The presented results correspond with the temperature distributions over the cooled surface after $60 \mathrm{~s}$ (fig. 2) and $100 \mathrm{~s}$ (fig. 3) of cooling.

In figures 7, 8 and 9 the variations of the heat transfer coefficient versus plate surface temperature for different distances from the nozzle axis (given by the radius $r$ ) have been presented. The highest values of HTC are observed for the distance from the nozzle axis from 16 to $46 \mathrm{~cm}$. In this area the water flow rate was the highest for the type of spray nozzle employed. 


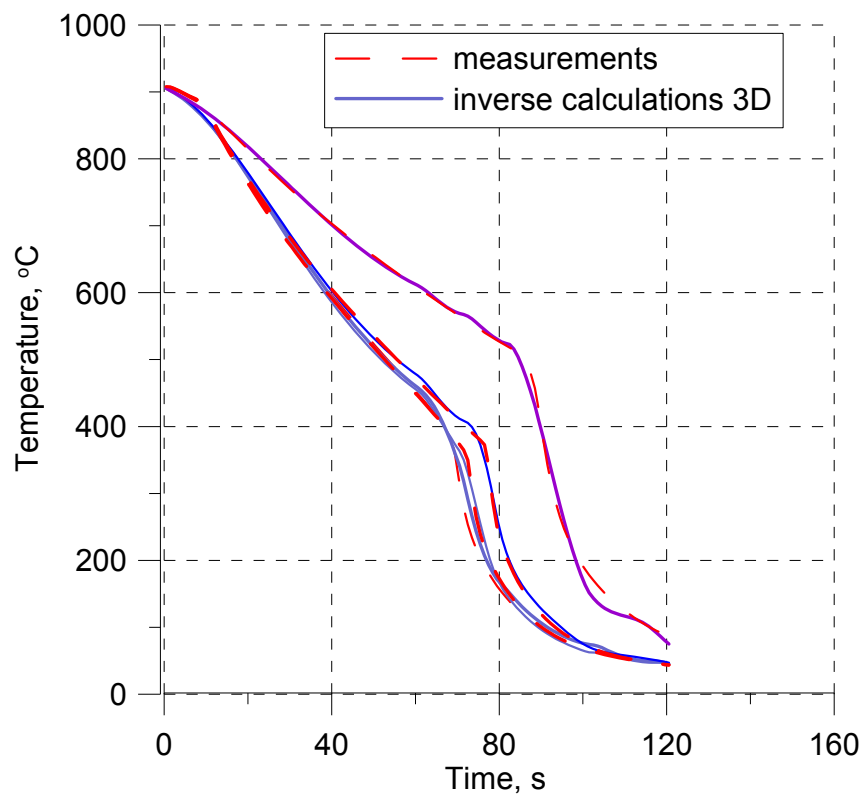

Figure 4: Comparison of the measured and calculated temperatures versus time of cooling for the thermocouples located at points: 13, 14, 15 and 16 .

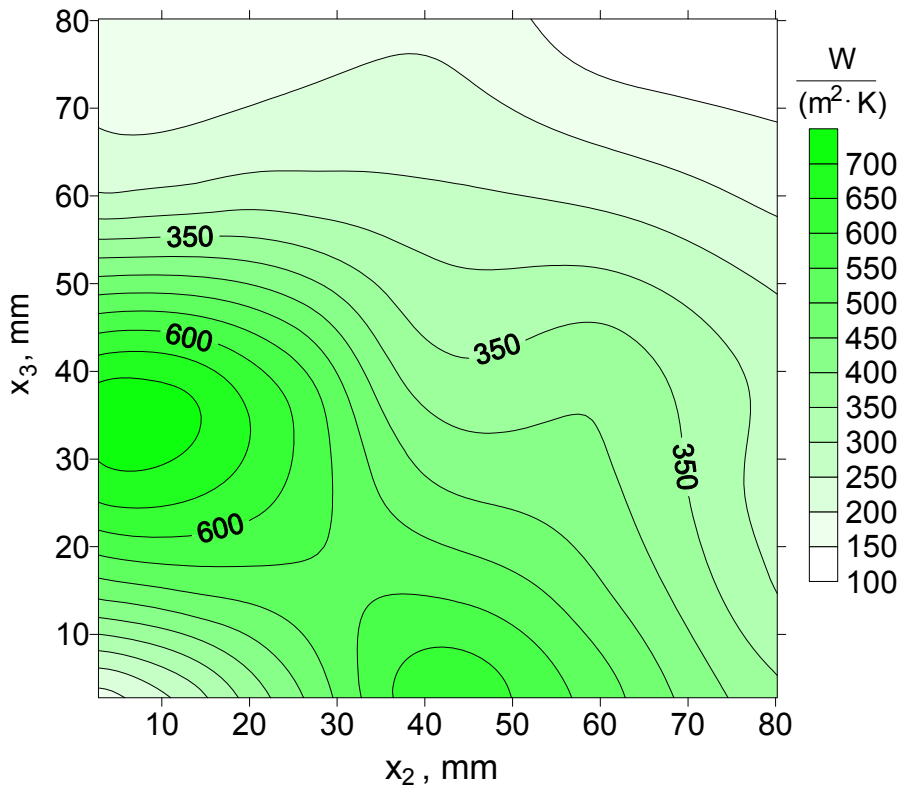

Figure 5: Heat transfer coefficient distribution over the cooled plate after $60 \mathrm{~s}$ of spray cooling process. 


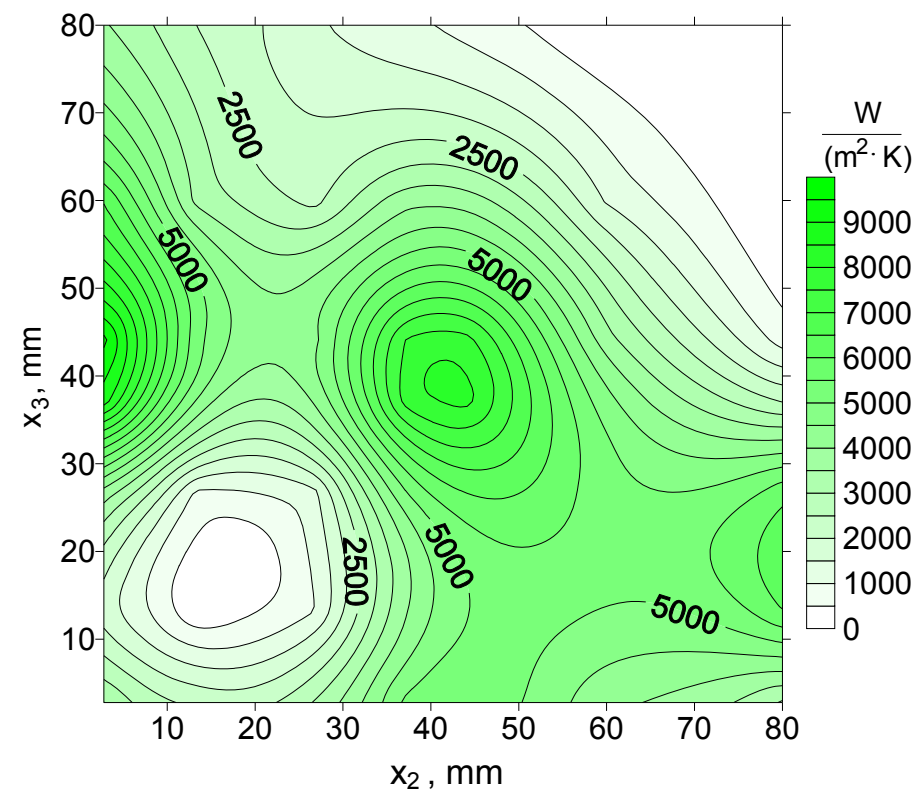

Figure 6: Heat transfer coefficient distribution over the cooled plate after $100 \mathrm{~s}$ of spray cooling process.

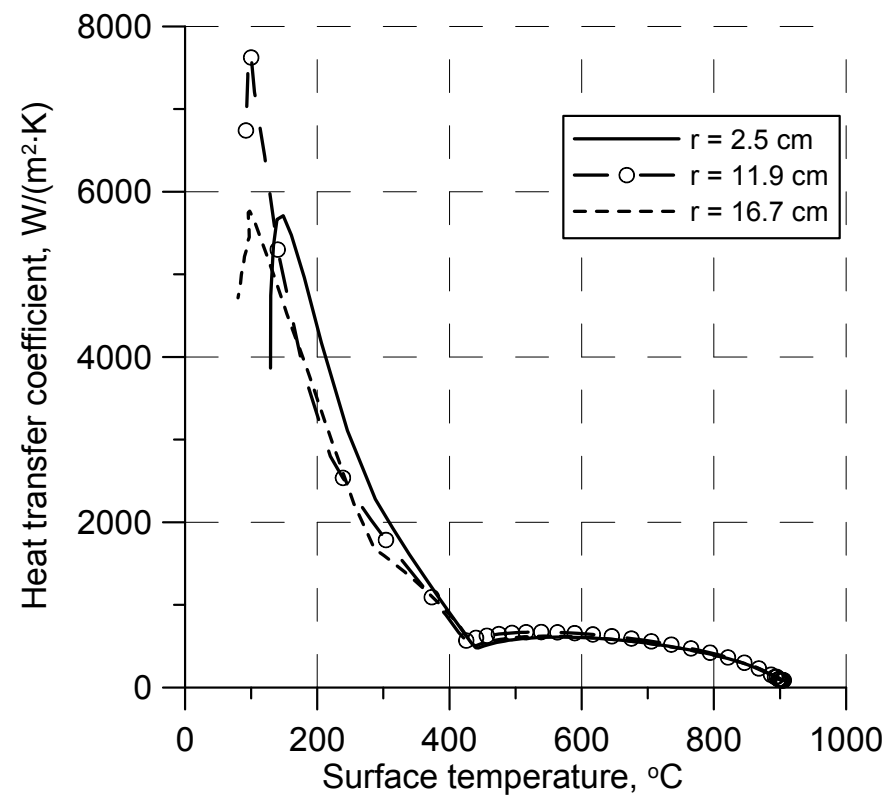

Figure 7: Dependence of the heat transfer coefficient on the surface temperature for the distances of: $2.5 \mathrm{~cm}, 11.9 \mathrm{~cm}$ and $16.7 \mathrm{~cm}$ from the nozzle axis. 


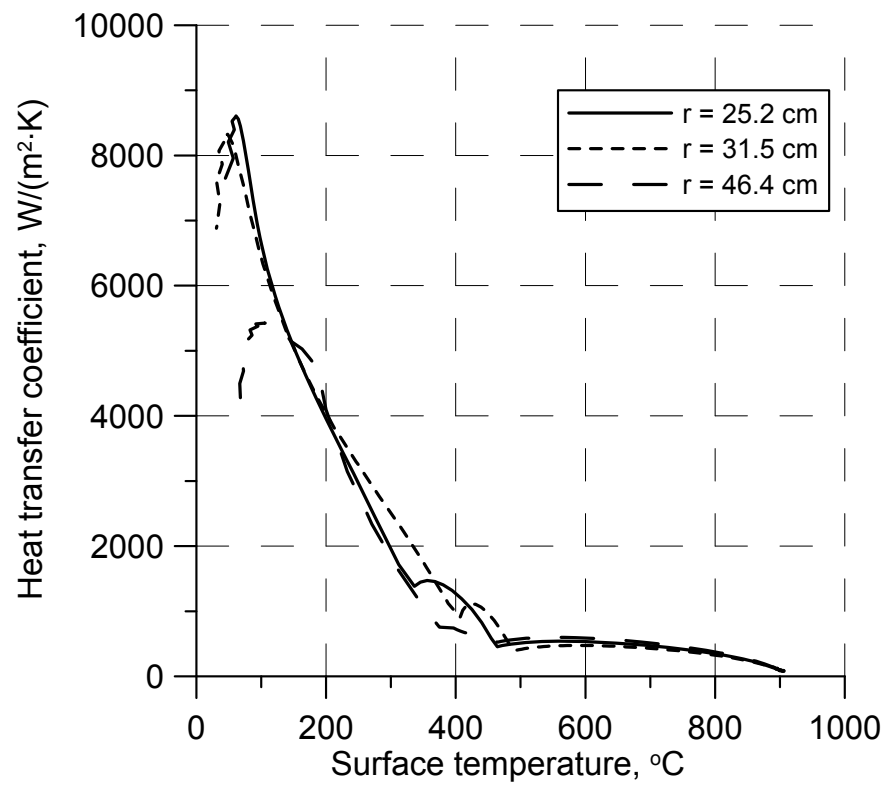

Figure 8: Dependence of the heat transfer coefficient on the surface temperature for the distances of: $25.2 \mathrm{~cm}, 31.5 \mathrm{~cm}$ and $46.4 \mathrm{~cm}$ from the nozzle axis.

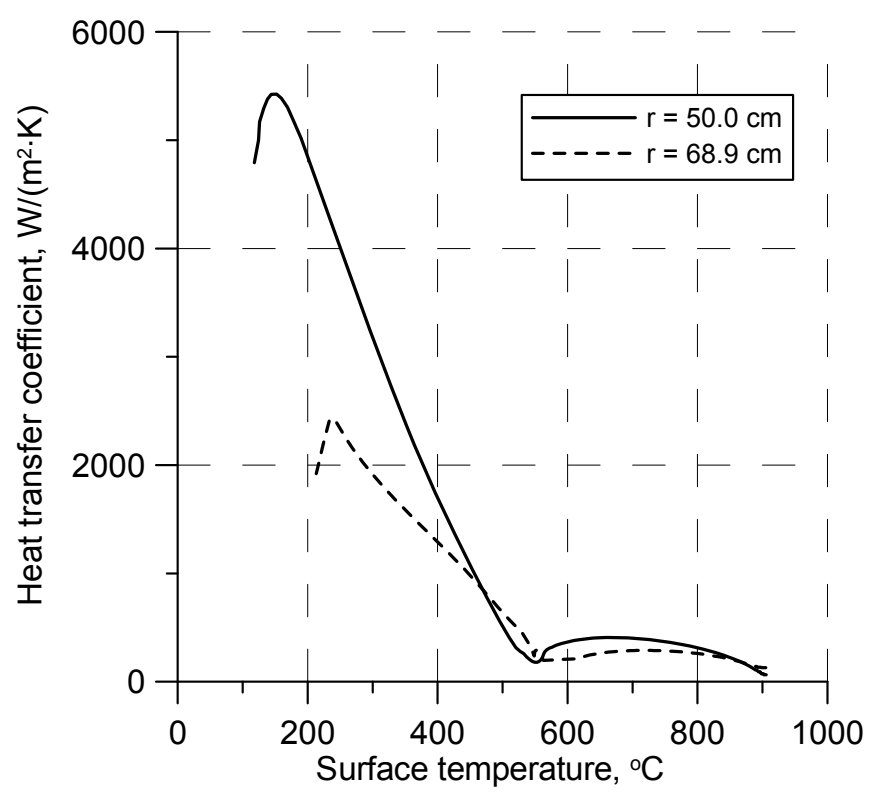

Figure 9: Dependence of the heat transfer coefficient on the surface temperature for the distances of: $50.0 \mathrm{~cm}$ and $68.9 \mathrm{~cm}$ from the nozzle axis. 
After $60 \mathrm{~s}$ of the spray cooling the heat transfer coefficient values are relatively low and do not exceed $700 \mathrm{~W} /\left(\mathrm{m}^{2} \cdot \mathrm{K}\right.$ ) (fig. 5). The plate surface temperature corresponding to the HTC does not exceed $680^{\circ} \mathrm{C}$ and is not lower than $400^{\circ} \mathrm{C}$ (fig. 2). Such results have been caused by the character of boiling phenomena that occurs at the cooled surface. In the range of surface temperatures between $900^{\circ} \mathrm{C}$ and $400^{\circ} \mathrm{C}$ the film boiling process takes place. That results in low variations of HTC values (figs. 5 and 7-9). When the plate surface temperature dropped below $400^{\circ} \mathrm{C}$ the heat transfer process at the cooled surface has entered the transition and nucleate boiling regime. It has resulted in significant increase in HTC values. That phenomenon is observed for all points located in the area covered by the water flux (figs. 7-9). It is also observed in the surface temperature distribution and in the heat transfer coefficient distribution obtained after $100 \mathrm{~s}$ of cooling process (figs. 3 and 6)

Not exactly axially symmetrical shape of the contour lines of the HTC distribution observed in figures 5 and 6 has resulted from non-symmetrical distribution of the water flux caused by the gravity forces.

\section{Summary}

The conducted experiment and the inverse solution have allowed to determine the heat transfer coefficient distribution as a function of the distance from the spray nozzle axis while spray cooling of the hot steel plate. The three dimensional finite element method based on nonlinear shape functions has been employed for the inverse calculation of the heat transfer coefficient. Dedicated heat transfer models and software have been developed to determine the heat flux distribution over the cooled surface of the vertical plate. The form of the boundary condition suitable to describe the heat transfer coefficient for arbitrary water spray nozzle has been proposed. The presented inverse method is well suited to determine a thermal characteristic of a single spray nozzle as well as for the set of nozzles.

\section{References}

[1] Malinowski Z., Telejko T., Hadała B., Cebo-Rudnicka A., Implementation of the axially symmetrical and three dimensional finite element models to the determination of the heat transfer coefficient distribution on the hot plate surface cooled by the water spray nozzle, Key Engineering Materials, 504-506, 1055-1060, 2012.

[2] Tacke G., Litzke H., Raquest E., Investigation into the Efficiency of Cooling System for Wide-Strip Hot Rolling Mills and Computer-Aides Control of Strip Cooling, in: P. D. Sothwick (Ed.), Proceedings of a Symposium on Accelerated Cooling of Steel, The Metallurgical Society of AIME, Pittsburgh, Pennsylvania, August 19-21, 35-54, 1985.

[3] Bejan A., Convection heat transfer, Hoboken, New Jersey, John Wiley \& Sons 2004. 
[4] Webb B. D., Ma C.F., Single-phase liquid jet impingement heat transfer, Advances in Heat transfer, 26, 105-207, 1995.

[5] PNR, Steel work nozzles, www.pnr.eu 